\title{
Integration of microarray profiles associated with cardiomyopathy and the potential role of Ube3a in apoptosis
}

\author{
JIE ZHANG ${ }^{1 *}$, RUI SONG ${ }^{1 *}$, YANFEI LI ${ }^{1}$, JIAN FENG $^{1}$, LUYING PENG $^{2}$ and JUE LI ${ }^{1}$ \\ ${ }^{1}$ Division of Preventive Medicine; ${ }^{2}$ Key Laboratory of Arrhythmias, Ministry of Education, \\ Tongji University School of Medicine, Shanghai 200092, P.R. China
}

Received August 9, 2013; Accepted December 3, 2013

DOI: $10.3892 / \mathrm{mmr} .2013 .1848$

\begin{abstract}
Cardiomyopathy is the one of the primary causes of mortality. High-throughput genome datasets provide novel information that aids the understanding of the complex mechanisms involved in cardiomyopathy. However, the causative mechanisms underlying cardiomyopathy are yet to be elucidated. In order to improve the use of the high-throughput genome datasets, the present study employed 9 microarray datasets to mine for differentially expressed cardiomyopathy-associated genes using bioinformatic methods. Following validation using quantitative polymerase chain reaction, ubiquitin-protein ligase E3a (Ube3a) was selected as a candidate gene for the disease. Substantial evidence suggests that apoptosis may be involved in the pathophysiology of cardiomyopathies. Therefore, in the present study, $\mathrm{H}_{2} \mathrm{O}_{2}$ was utilized to induce apoptosis in $\mathrm{H} 9 \mathrm{C} 2$ cells in order to understand the interrelation between Ube3a and the apoptosis-related protein p53. Ube $3 \mathrm{a}$ and $\mathrm{p} 53$ were observed to be significantly increased at the transcriptional and translational levels in response to $\mathrm{H}_{2} \mathrm{O}_{2}$ treatment. The results of this study indicate the efficiency of the data integration and the significant interrelation between Ube $3 \mathrm{a}$ and p53 in myocardial cells during apoptosis.
\end{abstract}

\section{Introduction}

Cardiomyopathy has been one of the primary causes of mortality over the past decade; however, the mechanism underlying the development of cardiomyopathy remains unclear. In vivo and in vitro studies have demonstrated that multiple gene networks, as well as factors other than blood pressure, may be involved during the initiation of cardiac

Correspondence to: Dr Jie Zhang or Professor Jue Li, Division of Preventive Medicine, Tongji University Medical School, 1239 Siping Road, Shanghai 200092, P.R. China

E-mail: jiezhang@tongji.edu.cn

E-mail: jueli@tongji.edu.cn

*Contributed equally

Key words: Ube3a, cardiomyopathy, ubiquitin, apoptosis, $\mathrm{H}_{2} \mathrm{O}_{2}$ hypertrophy $(1,2)$. Apoptosis has been suggested to be a major contributor to heart failure, with myocyte apoptosis observed during acute cardiac dysfunction (3). Furthermore, the apoptotic marker, $\mathrm{p} 53$, is significantly increased during cardiac hypertrophy $(4,5)$.

In normal cells, protein metabolism is a dynamic process of continuous degradation and re-synthesis. The ubiquitin-proteasome system is responsible for between 80 and $90 \%$ of this degradation. Alterations in the ubiquitin pathway have been reported to lead to protein metabolism disorders, which may lead to cardiomyopathy $(4,6)$. Weekes et al $(7)$ proposed that abnormalities in the ubiquitin system may cause myocardial hypertrophy and dilated cardiomyopathy.

Ubiquitin-protein ligase E3a (Ube3a) is an ubiquitin ligase that is responsible for recognizing target proteins in the ubiquitin-proteasome pathway. Ube3a is expressed in a number of tissues, including, the heart, liver and brain (GeneCards ${ }^{\circledR}$; www.genecards.org). Since 1997, research has predominantly focused on the role of Ube3a in Angelman Syndrome $(8,9)$. However, the role of Ube3a has also been investigated in Prader-Willi syndrome (10), autism (11) and Huntington's disease (12). In neural cells, Ube3a is capable of initiating the degradation of p53 in the ubiquitin-mediated pathway $(13,14)$. Furthermore, in hypertrophic myocardial tissue, mouse double minute 2 homolog (Mdm2), a member of the E3 family, is significantly increased and has been proposed to regulate the expression of p53 (14).

In the present study, $\mathrm{H}_{2} \mathrm{O}_{2}$ was used to induce apoptosis in $\mathrm{H} 9 \mathrm{C} 2$ cardiomyocytes. The pattern of Ube $3 \mathrm{a}$ and p53 expression was analyzed to assess their roles in cardiomyocyte apoptosis. To the best of our knowledge, this is the first report to demonstrate an association between Ube $3 \mathrm{a}$ and p53 upon $\mathrm{H}_{2} \mathrm{O}_{2}$ treatment in $\mathrm{H} 9 \mathrm{C} 2$ cardiomyocytes. Ube $3 \mathrm{a}$ and $\mathrm{p} 53$ may have a significant role in ubiquitin degradation in cardiomyocyte apoptosis.

\section{Materials and methods}

Data pre-processing and normalization. A total of 9 cardiomyopathy datasets were analyzed, including six oligonucleotide and three cDNA microarray datasets. The first oligonucleotide microarray dataset (GDS411) (15) consisted of 53 samples, including 12 normal, 12 heart failure, 12 rescue heart failure and 17 other types of samples. The second dataset (GDS651) 
comprised 37 samples, including 11 normal, 15 idiopathic dilated and 11 ischemic cardiomyopathy (ICM) samples. The third dataset (GDS1264) (16) consisted of 23 samples, including 11 normal and 12 cardiomyopathy samples. The fourth dataset (GDS1362) (17) contained 30 samples, including 15 normal and 15 ICM samples. The fifth dataset (GDS3386) $(18,19)$ contained 32 samples, including 16 normal and 16 myocardial hypertrophy samples. The sixth dataset (GDS2145) (20) consisted of 28 samples, including 15 normal and 13 dilated cardiomyopathy samples. Regarding the cDNA microarray datasets, the first dataset (GDS2206) (21) comprised 20 samples, including normal samples and those from patients with myocardial infarction (MI). The second dataset (GSE1616) (22) consisted of 37 samples, from six normal and 21 nonischemic patients, as well as 10 patients with ICM. The third dataset (GSE18224) (23) contained 24 samples, including 12 normal and 12 MI samples.

The cDNA data was $\log _{2}$-transformed and each array was subsequently normalized as median zero and standard deviation (SD) one per array, as adopted from the Oncomine database (24). CloneIDs with a missing rate $>20 \%$ were deleted. The remaining missing values were replaced using the $k$ nearest neighbor imputation algorithm $(k=15)(25)$. The Affymetrix GeneChip data were pre-processed using the robust multi-array analysis algorithm and then the between-array median was normalized (26).

Selection of differentially expressed genes (DEGs). The significance analysis of microarrays (SAM) method was performed using the samr R package (27) to select DEGs. Multiple statistical tests were controlled by false discovery rate (FDR), defined as the expected percentage of false positives among the claimed DEGs (28). The FDR estimation of SAM may be overly conservative $(29,30)$; therefore, the FDR estimation method suggested by Zhang (30) and influenced by Xie et al (29), was also employed and referred to as the modified SAM method.

Cell cultures. H9C2 cells (Chinese Academy of Sciences, Shanghai, China) were cultured on 96-well plates in Dulbecco's modified Eagle's Medium (DMEM) containing $1 \mathrm{~g} / 1$ glucose supplemented with $10 \%$ heat-inactivated fetal bovine serum (Wisent Bioproducts, St. Bruno, QC, Canada), 100 U/ml penicillin and $100 \mu \mathrm{g} / \mathrm{ml}$ streptomycin (Invitrogen Life Technologies, Carlsbad, CA, USA) in a humidified atmosphere at $37^{\circ} \mathrm{C}$ in $5 \% \mathrm{CO}_{2}$. To prevent cell loss, cells were subcultured prior to confluence, at a ratio of $\sim 1: 2$, every two days. Cells in the logarithmic growth phase were used in the experiments.

$\mathrm{H}_{2} \mathrm{O}_{2}$ treatment. Following inoculation for $24 \mathrm{~h}, \mathrm{H} 9 \mathrm{C} 2$ cells were treated with the indicated concentrations of $\mathrm{H}_{2} \mathrm{O}_{2}$ (Sangon Biotech, Shanghai, China), which was added to the culture medium. Cells were then incubated further for the indicated times.

Cell viability. Following exposure to $\mathrm{H}_{2} \mathrm{O}_{2}$ for $4 \mathrm{~h}$, H9C2 cells were treated with MTT (Nanjing KeyGen Biotech Co. Ltd., Nanjing, China) and then incubated for $4 \mathrm{~h}$ at $37^{\circ} \mathrm{C}$ in the dark. The supernatant was subsequently removed and $150 \mu \mathrm{l}$ dimethylsulfoxide was added to each well. The optical density (OD) was measured at a wavelength of $550 \mathrm{~nm}$ once the crystals had dissolved. Cell viability was calculated as the percentage of the control OD.

Apoptosis assay. The percentage of apoptotic cells was measured using the Annexin V-fluorescein isothiocyanate (FITC) Apoptosis Detection kit (Nanjing KeyGen Biotech Co. Ltd.) according to the manufacturer's instructions. Following exposure to $\mathrm{H}_{2} \mathrm{O}_{2}$ for $48 \mathrm{~h}$, cells were harvested using $0.25 \%$ Trypsin without ethylenediaminetetraacetic acid, and then washed twice with phosphate-buffered saline (PBS), prior to resuspension in $500 \mu \mathrm{l}$ binding buffer with $5 \mu \mathrm{l}$ Annexin V-FITC and $5 \mu 1$ propidium iodide (PI). Subsequent to incubation for $15 \mathrm{~min}$ in the dark, the samples were analyzed using flow cytometry (BD Biosciences, Franklin Lakes, NJ, USA). The number of cells in different quadrants represented different cell populations, with the lower left quadrant representing normal cells, the lower right representing viable apoptotic cells, the upper right representing non-viable apoptotic cells and the upper left representing necrotic cells.

Western blot analysis. Subsequent to the relevant treatment, cells were washed twice with ice-cold PBS and then lysed in cell lysis buffer containing $1 \%$ phenylmethylsulfonyl fluoride (PMSF) for $30 \mathrm{~min}$ on ice. The lysate was centrifuged at $15,249 \mathrm{x}$ g at $4^{\circ} \mathrm{C}$ for $20 \mathrm{~min}$ to remove the insoluble materials, followed by collection of the supernatants. All samples were mixed with $5 \mathrm{X}$ loading buffer and boiled for $5 \mathrm{~min}$. Samples were separated using $8 \%$ SDS-PAGE and then transferred to polyvinylidene fluoride (PVDF) membranes (Billerica, Millipore, MA, USA). Membranes were blocked for $1 \mathrm{~h}$ using 5\% non-fat milk in Tris-buffered saline containing $1 \%$ Tween-20 (TBST) at room temperature and then incubated with anti-UBE3A (Cell Signaling Technology, Danvers, MA, USA), anti-p53 (BioWorld Products Inc., Visalia, CA, USA) and anti-GAPDH (Epitomics Inc., Burlingame, CA, USA) antibodies overnight at $4^{\circ} \mathrm{C}$. Membranes were washed with TBST three times every $10 \mathrm{~min}$, then incubated with a horseradish peroxidase-conjugated secondary antibody (Beyotime Institute of Technology, Haimen, China) for $1 \mathrm{~h}$ at room temperature. Following the secondary antibody incubation, membranes were further washed with TBST and the immunoreactive bands were visualized using the enhanced chemiluminescence method. The images were analyzed using the Quantity One ${ }^{\circledR}$ software (Bio-Rad, Hercules, CA, USA).

Quantitiative polyermase chain reaction ( $q P C R$ ) analysis. RNA was prepared using TRIzol ${ }^{\circledR}$ Reagent (Invitrogen Life Technologies) and RNA concentration and purity were then determined using a spectrophotometer (Thermo Fisher Scientific, Waltham, MA, USA). Total RNA was subsequently converted into cDNA by reverse transcription using the High-Capacity cDNA Reverse Transcription kit (Applied Biosystems, Carlsbad, CA, USA). qPCR was performed in triplicate using Power SYBR ${ }^{\circledR}$ Green PCR Master mix and a 7500 Fast Real-Time PCR system (Applied Biosystems) according to the manufacturer's instructions. Analysis was performed using the software supplied with the instrument. Primer sequences were as follows: Forward: 5'-GAGGACTCG GAAAATTGAAGATG-3' and reverse: 5'-CCGGAAGTA 
Table I. Number of differentially expressed genes selected from different datasets (FDR control values).

\begin{tabular}{lrrrr}
\hline ID & $<0.001$ & $<0.01$ & $<0.05$ & $<0.1$ \\
\hline GDS411 & 6 & 6 & 7 & 18 \\
GDS651 & 155 & 1656 & 6407 & 10497 \\
GDS1264 & 93 & 259 & 869 & 1721 \\
GDS1362 & 66 & 405 & 2067 & 5136 \\
GDS3386 & 5 & 5 & 5 & 19 \\
GDS2145 & 304 & 818 & 1637 & 2130 \\
GDS2206 & 941 & 2648 & 5491 & 7480 \\
GSE1616 & 78 & 203 & 751 & 1259 \\
GSE18224 & 89 & 290 & 904 & 1411 \\
\hline
\end{tabular}

AAAGGACATTAAAGC-3' for Ube3a; and forward: 5'-CCA TCAACGACCCCTTCATT-3' and reverse: 5'-GACCAG CTTCCCATTCTCAG-3' for GAPDH.

Statistical analysis. Statistical analyses were performed using the SPSS 14.0 statistical software (SPSS, Inc., Chicago, IL, USA). All data are expressed as the mean \pm SEM from at least three independent experiments. Results were analyzed using one-way analysis of variance. $\mathrm{P}<0.05$ was considered to indicate a statistically significant difference.

Experimental procedures. Each experiment was repeated at least three times with comparable results, unless indicated otherwise.

\section{Results}

DEG selection. Current FDR control procedures, including that adopted in SAM (27), may be unstable in small samples particularly in the presence of correlated expression changes. Therefore, in the present study, the actual FDR of DEGs detected in simulated small samples was evaluated, according to predefined DEGs. Based on the simulated results, using SAM with $0.05 \%$ FDR control, the DEGs obtained from the full samples were defined as a nominal gold standard set (31). As shown in Table I, this procedure identified various DEGs. Although false positives were detected in the selected DEGs, this was a preliminary procedure to prepare for the subsequent analysis of various datasets.

Generation of cardiomyopathy-associated E3 ubiquitin ligase genes. Different datasets supply different information. The DEGs selected using the aforementioned method were associated with numerous cardiomyopathy-associated genes. A total of five DEGs were selected, all of which belong to the E3 ubiquitin ligase family, and were termed cardiomyopathy-associated E3 ubiquitin ligase genes. These DEGs were: Ube3a; WW domain containing E3 ubiquitin protein ligase 1 (Wwp1); itchy E3 ubiquitin protein ligase (Itch); HECT, C2 and WW domain containing E3 ubiquitin protein ligase 1 (Kiaa0322) and SMAD specific E3 ubiquitin protein ligase 2 (Smurf2). The mRNA levels of these five candidate genes were detected using qPCR

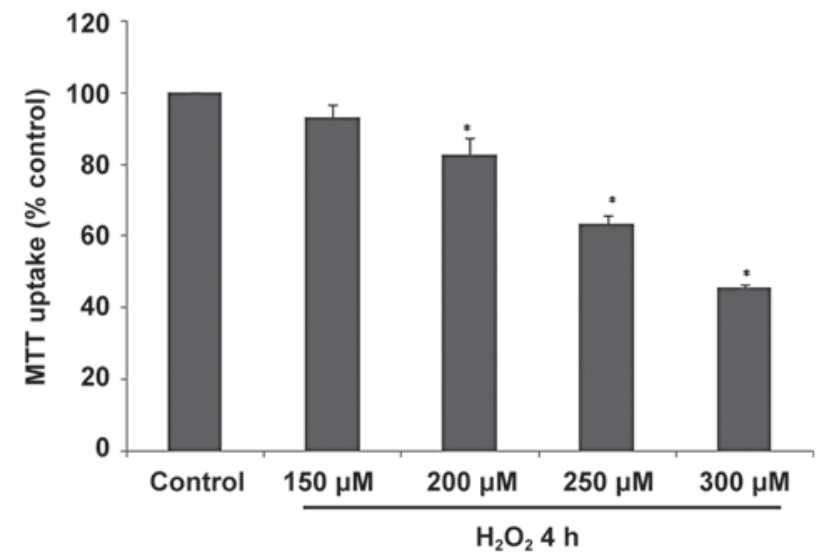

Figure 1. High concentrations of $\mathrm{H}_{2} \mathrm{O}_{2}$ affect cell viability. $\mathrm{H} 9 \mathrm{C} 2$ cells were exposed to various concentrations of $\mathrm{H}_{2} \mathrm{O}_{2}$ ranging from 150 to $300 \mu \mathrm{M}$ for $4 \mathrm{~h}$ and cell viability was assessed by MTT uptake. Cell activity decreased in a dose-dependent manner. Datasets are presented as the mean \pm standard error of the mean of three independent measurements. ${ }^{*} \mathrm{P}<0.05$ compared with the control.

analysis. Ube3a mRNA levels were observed to be significantly higher in the $\mathrm{H}_{2} \mathrm{O}_{2}$-treated group than in the control group; therefore, Ube3a was selected as a candidate myocyte apoptosis-associated gene for further investigation.

$\mathrm{H}_{2} \mathrm{O}_{2}$ exposure decreases cell viability in $\mathrm{H} 9 \mathrm{C} 2$ cells. $\mathrm{H} 9 \mathrm{C} 2$ cells were exposed to increasing concentrations of $\mathrm{H}_{2} \mathrm{O}_{2}$ ranging between 150 and $300 \mu \mathrm{M}$ for $4 \mathrm{~h}$. Cell viability was then assessed by MTT uptake. The results showed that in the $\mathrm{H}_{2} \mathrm{O}_{2}$-treated group, cell viability decreased in a dose-dependent manner compared with the PBS-treated control group (Fig. 1).

$\mathrm{H}_{2} \mathrm{O}_{2}$ exposure induces apoptosis in $\mathrm{H} 9 \mathrm{C} 2$ cells. Reports have shown that $\mathrm{H}_{2} \mathrm{O}_{2}$ is capable of inducing myocardial hypertrophy at low concentrations and apoptosis at higher concentrations (32). Annexin V/PI staining and flow cytometry were used to determine the apoptotic response of $\mathrm{H} 9 \mathrm{C} 2$ cells to high concentrations of $\mathrm{H}_{2} \mathrm{O}_{2}$. Cells were harvested following exposure to $\mathrm{H}_{2} \mathrm{O}_{2}(150-250 \mu \mathrm{M})$ for $4 \mathrm{~h}$. As shown in Fig. 2A-D, the Annexin V/PI point diagram exhibited a significant dose-dependent increase in apoptotic cells in response to $\mathrm{H}_{2} \mathrm{O}_{2}$. Following treatment with $250 \mu \mathrm{M} \mathrm{H}_{2} \mathrm{O}_{2}$ for $4 \mathrm{~h}$, the percentage of apoptotic H9C2 cells increased approximately five-fold compared with the PBS-treated control cells (Fig. 2E). These results suggest that $\mathrm{H}_{2} \mathrm{O}_{2}$ exposure is capable of inducing apoptosis in a dose-dependent manner in $\mathrm{H} 9 \mathrm{C} 2$ cells.

Ube3a transcription and translation increase in response to apoptosis in $\mathrm{H} 9 \mathrm{C} 2$ cells. To examine the effect of $\mathrm{H}_{2} \mathrm{O}_{2}$-induced apoptosis on Ube3a levels in $\mathrm{H} 9 \mathrm{C} 2$ cells, cells were treated with $\mathrm{H}_{2} \mathrm{O}_{2}$ in accordance with the aforementioned method. Ube3a protein levels were observed to increase in the same manner as that of p53 (Fig. 3). An increase in Ube3a transcription was also observed following $\mathrm{H}_{2} \mathrm{O}_{2}$ treatment (Fig. 4).

\section{Discussion}

The mechanism underlying cardiomyopathy is complex and its initiating mechanisms have yet to be elucidated. Different 

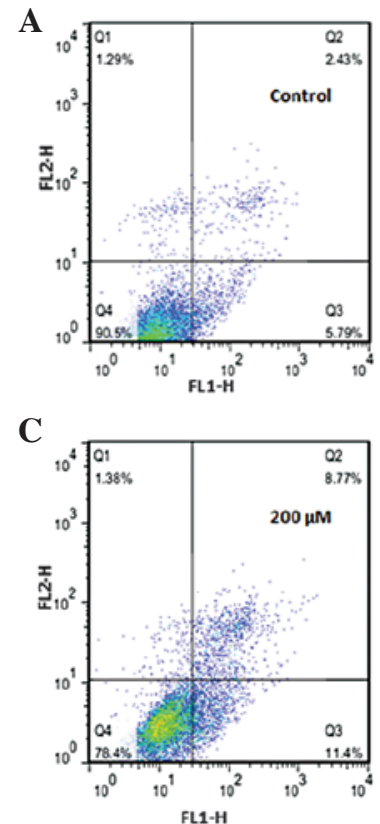

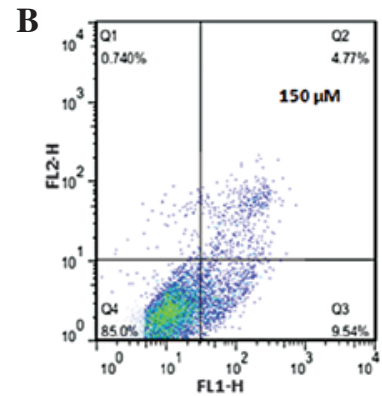

D

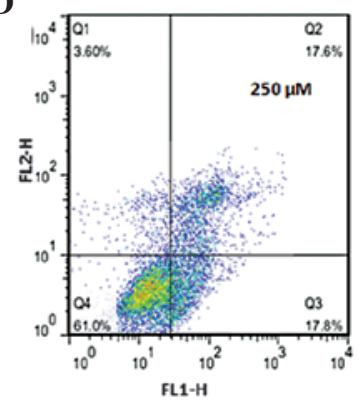

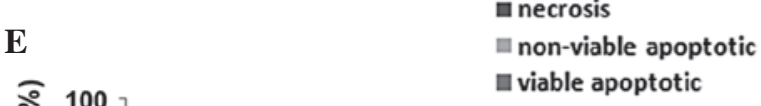

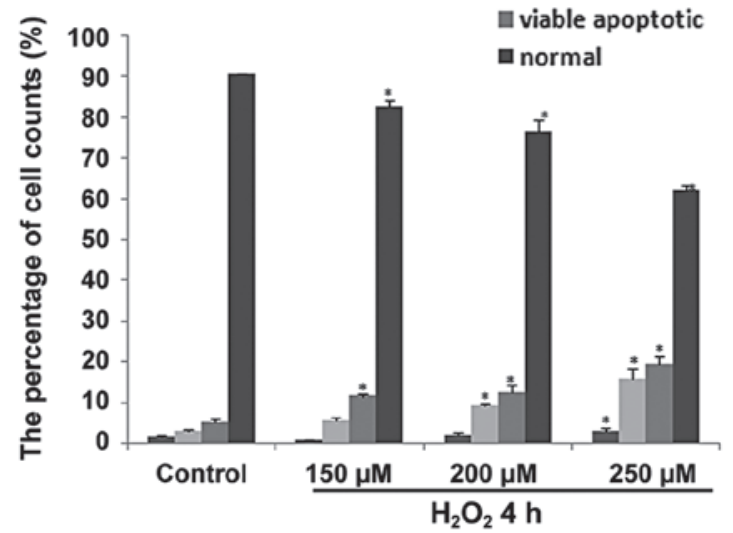

Figure 2. High concentrations of $\mathrm{H}_{2} \mathrm{O}_{2}$ induce apoptosis in $\mathrm{H} 9 \mathrm{C} 2$ cells. Cells were treated with $\mathrm{H}_{2} \mathrm{O}_{2}$ for 4 h, prior to apoptosis being detected using an Annexin V/PI assay and flow cytometry. The negative control was treated with an equal volume of hosphate-buffered saline. (A-D) H9C2 cells treated with 0, 150, 200 and $250 \mu \mathrm{M} \mathrm{H}_{2} \mathrm{O}_{2}$ for $4 \mathrm{~h}$, respectively. Q1 represents necrotic cells; Q2 represents non-viable apoptotic cells; Q3 represents normal cells and Q4 represents viable apoptotic cells. (E) Densitometry of cell counts. The number of apoptotic cells increased in a dose-dependent manner in response to $\mathrm{H}_{2} \mathrm{O}_{2}$ treatment for $4 \mathrm{~h}$. Data are presented as the mean \pm standard error of the mean of three independent measurements. * $\mathrm{P}<0.05$ compared with the control. $\mathrm{Q}$, quadrant; PI, propidium iodide.

A

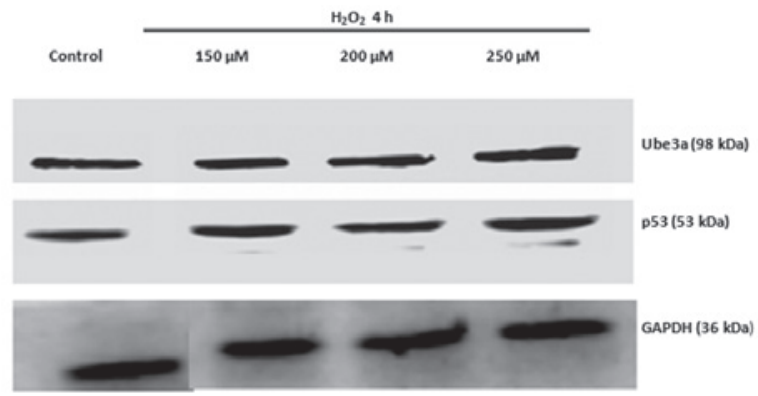

B

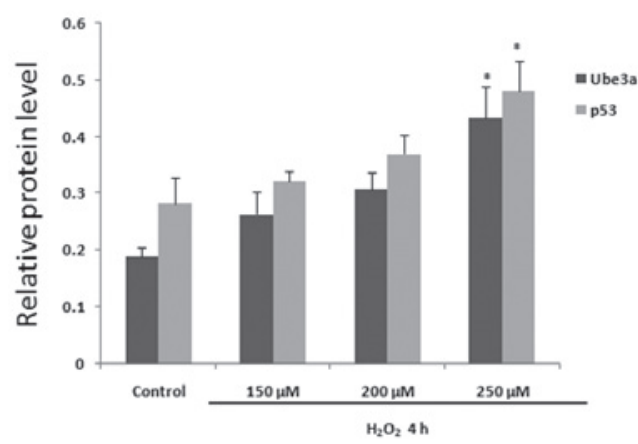

Figure 3. Ube3a translation increases upon $\mathrm{H}_{2} \mathrm{O}_{2}$-induced apoptosis. $\mathrm{H} 9 \mathrm{C} 2$ cells were treated with 150,200 and $250 \mu \mathrm{M} \mathrm{H}_{2} \mathrm{O}_{2}$ for $4 \mathrm{~h}$. (A) Dose-dependent effects of $\mathrm{H}_{2} \mathrm{O}_{2}$ on Ube3a and p53 protein levels. (B) Densitometry of Ube3a and p53 protein levels upon treatment with $\mathrm{H}_{2} \mathrm{O}_{2}$. GAPDH was used as a loading control. Values are presented as the mean \pm standard error of the mean of three independent experiments. ${ }^{*} \mathrm{P}<0.05$ compared with the control. Ube3a, ubiquitin-protein ligase E3a.

datasets supply different information; therefore, in the present study, several microarray datasets were integrated and Ube3a was selected as a cardiomyopathy-associated gene. Substantial

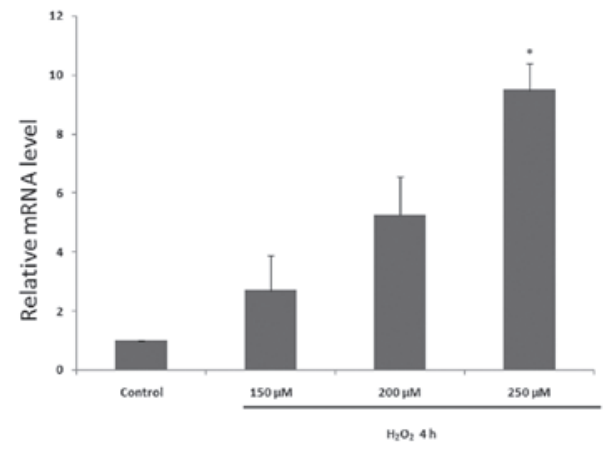

Figure 4. Ube3a transcription increases upon $\mathrm{H}_{2} \mathrm{O}_{2}$-induced apoptosis. $\mathrm{H} 9 \mathrm{C} 2$ cells were treated with 150,200 and $250 \mu \mathrm{M} \mathrm{H}_{2} \mathrm{O}_{2}$ for $4 \mathrm{~h}$. Dose-dependent effects of $\mathrm{H}_{2} \mathrm{O}_{2}$ on Ube3a mRNA levels. Values are presented as the mean \pm standard error of the mean of three independent experiments. ${ }^{*} \mathrm{P}<0.05$ compared with the control. Ube3a, ubiquitin-protein ligase E3a.

evidence has suggested that apoptosis may be involved in the pathophysiology of cardiomyopathies; therefore, in the present study, $\mathrm{H}_{2} \mathrm{O}_{2}$ was used to induce apoptosis in $\mathrm{H} 9 \mathrm{C} 2$ cells to assess whether Ube $3 \mathrm{a}$ is responsible for degrading the apoptotic protein, p53.

In this study, $\mathrm{H} 9 \mathrm{C} 2$ cell viability was found to decrease in a dose-dependent manner upon $4 \mathrm{~h}$ of exposure to $\mathrm{H}_{2} \mathrm{O}_{2}$ at concentrations ranging between 150 and $300 \mu \mathrm{M}$, detected using MTT assay (Fig. 1). In order to detect whether apoptosis occurred under these conditions, flow cytometry was used. $\mathrm{H}_{2} \mathrm{O}_{2}$ treatment at concentrations ranging between 150 and $250 \mu \mathrm{M}$ for $4 \mathrm{~h}$ was observed to induce apoptosis in a dose-dependent manner in H9C2 cells (Fig. 2). p53 protein levels were also observed to increase upon induction of 
apoptosis. These results demonstrated that apoptosis occurred under $\mathrm{H}_{2} \mathrm{O}_{2}$ stimulation in $\mathrm{H} 9 \mathrm{C} 2$ cells. Furthermore, the transcriptional and translational levels of Ube3a were increased in a similar manner to that of p53 (Figs. 3 and 4), suggesting that an association may exist between Ube $3 \mathrm{a}$ and apoptosis.

Based on the results in the present study, it was hypothesized that Ube3a may have an important role in the process of cardiomyopathy. Ube3a is a member of the E3 family, which is responsible for recognizing target proteins in the ubiquitin-proteasome pathway. The ubiquitin proteasome system has an important role in the process of protein metabolism in normal cells. Therefore, it was hypothesized in the present study that when Ube3a protein levels are altered, homeostasis of the ubiquitin-proteasome system may be lost. This may induce abnormalities in protein degradation and ultimately lead to apoptosis or cardiomyopathy. Many researches are focusing on the potential role of Ube3a at the brain, particulary Angelman syndrome. The present study is the first time that novel function of Ube3a has been reported in the heart, which is likely to reveal its new features in cardiomyopathy.

\section{Acknowledgements}

The authors would like to thank the staff involved in the study for their valued contributions. This study was supported by the Young Talents Scheme of Tongji University (no. 1500219046) and the Shanghai Municipal Health Bureau Project (no. z0124y166).

\section{References}

1. Sarkar S, Leaman DW, Gupta S, et al: Cardiac overexpression of myotrophin triggers myocardial hypertrophy and heart failure in transgenic mice. J Biol Chem 279: 20422-20434, 2004.

2. Schaub MC, Hefti MA and Zaugg M: Integration of calcium with the signaling network in cardiac myocytes. J Mol Cell Cardiol 41 183-214, 2006.

3. Sarkar S, Chawla-Sarkar M, Young D, et al: Myocardial cell death and regeneration during progression of cardiac hypertrophy to heart failure. J Biol Chem 279: 52630-52642, 2004.

4. Shi PP, Cao XR, Sweezer EM, et al: Salt-sensitive hypertension and cardiac hypertrophy in mice deficient in the ubiquitin ligase Nedd4-2. Am J Physiol Renal Physiol 295: F462-F470, 2008

5. Haupt S, Berger M, Goldberg Z and Haupt Y: Apoptosis - the p53 network. J Cell Sci 116: 4077-4085, 2003.

6. Li HH, Willis MS, Lockyer P, et al: Atrogin-1 inhibits Akt-dependent cardiac hypertrophy in mice via ubiquitin-dependent coactivation of Forkhead proteins. J Clin Invest 117: 3211-3223, 2007.

7. Weekes J, Morrison K, Mullen A, Wait R, Barton P and Dunn MJ: Hyperubiquitination of proteins in dilated cardiomyopathy. Proteomics 3: 208-216, 2003.

8. Matsuura T, Sutcliffe JS, Fang P, et al: De novo truncating mutations in E6-AP ubiquitin-protein ligase gene (UBE3A) in Angelman syndrome. Nat Genet 15: 74-77, 1997.

9. Huang HS, Allen JA, Mabb AM, et al: Topoisomerase inhibitors unsilence the dormant allele of Ube3a in neurons. Nature 481: 185-189, 2011.

10. Bürger J, Horn D, Tönnies H, Neitzel H and Reis A: Familial interstitial $570 \mathrm{kbp}$ deletion of the UBE3A gene region causing Angelman syndrome but not Prader-Willi syndrome. Am J Med Genet 111: 233-237, 2002.

11. Veenstra-VanderWeele J, Gonen D, Leventhal BL and Cook EH Jr: Mutation screening of the UBE3A/E6-AP gene in autistic disorder. Mol Psychiatry 4: 64-67, 1999.
12. Maheshwari M, Samanta A, Godavarthi SK, Mukherjee R and Jana NR: Dysfunction of the ubiquitin ligase Ube3a may be associated with synaptic pathophysiology in a mouse model of Huntington disease. J Biol Chem 287: 29949-29957, 2012.

13. Long X, Boluyt MO, Hipolito ML, et al: p53 and the hypoxia-induced apoptosis of cultured neonatal rat cardiac myocytes. J Clin Invest 99: 2635-2643, 1997.

14. Shi L, Nikolic D, Liu S, Lu H and Wang S: Activation of renal renin-angiotensin system in upstream stimulatory factor 2 transgenic mice. Am J Physiol Renal Physiol 296: F257-F265, 2009.

15. Blaxall BC, Spang R, Rockman HA and Koch WJ: Differential myocardial gene expression in the development and rescue of murine heart failure. Physiol Genomics 15: 105-114, 2003.

16. Rysä J, Leskinen H, Ilves $M$ and Ruskoaho H: Distinct upregulation of extracellular matrix genes in transition from hypertrophy to hypertensive heart failure. Hypertension 45: 927-933, 2005

17. da Silva R, Lucchinetti E, Pasch T, Schaub MC and Zaugg M: Ischemic but not pharmacological preconditioning elicits a gene expression profile similar to unprotected myocardium. Physiol Genomics 20: 117-130, 2004.

18. Fliegner D, Schubert C, Penkalla A, et al: Female sex and estrogen receptor-beta attenuate cardiac remodeling and apoptosis in pressure overload. Am J Physiol Regul Integr Comp Physiol 298: R1597-R1606, 2010.

19. Kararigas G, Fliegner D, Gustafsson JÅ and Regitz-Zagrosek V: Role of the estrogen/estrogen-receptor-beta axis in the genomic response to pressure overload-induced hypertrophy. Physiol Genomics 43: 438-446, 2011.

20. Barth AS, Kuner R, Buness A, et al: Identification of a common gene expression signature in dilated cardiomyopathy across independent microarray studies. J Am Coll Cardiol 48: 1610-1617, 2006.

21. Husberg $\mathrm{C}$, Nygård $\mathrm{S}$, Finsen $\mathrm{AV}$, et al: Cytokine expression profiling of the myocardium reveals a role for CX3CL1 (fractalkine) in heart failure. J Mol Cell Cardiol 45: 261-269, 2008.

22. Kittleson MM, Minhas KM, Irizarry RA, et al: Gene expression analysis of ischemic and nonischemic cardiomyopathy: shared and distinct genes in the development of heart failure. Physiol Genomics 21: 299-307, 2005.

23. Andersson KB, Florholmen G, Winer LH, Tønnessen T and Christensen G: Regulation of neuronal type genes in congestive heart failure rats. Acta Physiol (Oxf) 186: 17-27, 2006

24. Rhodes DR, Kalyana-Sundaram S, Mahavisno V, et al: Oncomine 3.0: genes, pathways, and networks in a collection of 18,000 cancer gene expression profiles. Neoplasia 9: 166-180, 2007.

25. Troyanskaya O, Cantor M, Sherlock G, et al: Missing value estimation methods for DNA microarrays. Bioinformatics 17: 520-525, 2001.

26. Irizarry RA, Warren D, Spencer F, et al: Multiple-laboratory comparison of microarray platforms. Nat Methods 2: 345-350, 2005.

27. Tusher VG, Tibshirani R and Chu G: Significance analysis of microarrays applied to the ionizing radiation response. Proc Natl Acad Sci USA 98: 5116-5121, 2001.

28. K l i p per-A u r a ch Y, Was serman M, Braunspiegel-Weintrob N, et al: Mathematical formulae for the prediction of the residual beta cell function during the first two years of disease in children and adolescents with insulin-dependent diabetes mellitus. Med Hypotheses 45: 486-490, 1995.

29. Xie Y, Pan W and Khodursky AB: A note on using permutation-based false discovery rate estimates to compare different analysis methods for microarray data. Bioinformatics 21: 4280-4288, 2005.

30. Zhang S: A comprehensive evaluation of SAM, the SAM R-package and a simple modification to improve its performance. BMC Bioinformatics 8: 230, 2007.

31. Pavlidis P, Li Q and Noble WS: The effect of replication on gene expression microarray experiments. Bioinformatics 19: 1620-1627, 2003.

32. Clerk A, Kemp TJ, Zoumpoulidou G and Sugden PH: Cardiac myocyte gene expression profiling during $\mathrm{H}_{2} \mathrm{O}_{2}$-induced apoptosis. Physiol Genomics 29: 118-127, 2007. 